\title{
A Study on the Movie Reviews on the Network New Media
}

\author{
Fangping Cheng ${ }^{1, \text { a }}$ \\ ${ }^{1}$ Yancheng Vocational Institute of Industry Technology, Yancheng City, Jiangsu Province, 224001, \\ China \\ a email:
}

Key words: Network New Media, Movie Reviews, Causes, Main Features, Development Advantages

\begin{abstract}
Nowadays, network new media has gradually formed a certain ideology, and the new network media film reviews have further received the attention of the masses, which provides a great stage for the survival and development of the film critics. Based on the author's work experience, this paper first discussed the reasons for the production of online movie reviews, then studied the main features shown by the online movie reviews, finally analyzed the development advantages of the online movie reviews.
\end{abstract}

\section{Introduction}

With the maturity of the Internet, a new form of online media film review is rising quietly, and many film reviews in the forum and blog get e more attention and love from the audience. As a result, the network movie reviews can effectively breakthrough the dilemma in the development process of the traditional movie reviews. At the same time, for a common goal, Online movie reviews and traditional movie reviews gather together, providing a solid and powerful force for the growth of the film review business.

\section{The Causes of Internet Movie Reviews}

The increasing development and expansion of Internet technology provides great support to the network media film reviews, which can make the network media film review have a better communication with the production of film works, and it will help to promote the rapid development of the film industry. We know that the Internet media film reviews are driven by the growth of the film industry, and the key point is the establishment of a new type of film criticism form on the information network media which faces the audience from all walks of life. It can be said that the Internet media film review is based on the decline of traditional film evaluation and driven by the new generation of people's internal demand.

\section{The Key Features of Online Movie Reviews}

The openness of the Internet Film Review. The Internet is based on freedom and openness, however, the film review on the new network media is based on the Internet which has a very strong openness. Film reviews on the Internet platform can implement the sharing of information resources, effectively breaking the previous media in the presence of many restrictions, for example, the newspapers and magazines for film critics are restricted because of the complex conditions. Obviously, books and newspapers will limit the size of the area, and it must be edited by the 
relevant editor, so there is no doubt that it gives various obstacles for the real reviews. On the broad masses of perspective, the traditional film is basically in a monopoly position, viewers simply can not be free to put forward any views on the merits of the film, there is no equal right to speak. However, it has got an a great change since the use of the new network media films, so it can be said that the online movie review has greatly expanded the space of freedom of speech, but also greatly enhance the openness of China's film reviews.

Online movie reviews have new ways and forms of communication. The Internet media film review got rid of the old form using text only for local communication, and a new form beyond the text of the film evaluation has been created, and it can also use audio, pictures, video and other forms to implement a series of new ways of film criticism, in this way, the majority of the audience can be able to carry out a full range of three-dimensional unique feelings, and it can also effective improve the network media film evaluation of a number of readers. In addition, it makes a distinction with the traditional film reviews. As a carrier of communication, books, newspapers have used information technology as a new carrier of communication, this digital mode changed the traditional model and it has brought more convenient to the general public.

Online movie reviews have a strong interaction. In the traditional form of film reviews, it is difficult to exchange and discussion between the film reviews and the audience. In general, it is the film evaluation staff that make some movie reviews for the audience to read, so it may cause the status that the two sides are very unequal. Some film critics can not be very good to meet the growing needs of the masses of the people, lack of effective communication between the film critics and the broad masses, which has seriously hindered the progress and development of China's film critics. However, the network media film review in the new situation has completely changed the traditional forms of communication, a single direction of the movie reviews is completely transformed into the effective interaction between film critics and the audience, which can make the different view and aesthetic value between audiences and movie critics be able to get direct expression, effectively expressing the inner feelings of the audience.

\section{The Development Advantages of Online Movie Reviews}

Internet movie reviews have a large number of users. Nowadays, with the widespread use of computers and the increasing use of the Internet, the masses already have a more active participation in the network of new media film reviews, and there are more people began to use the network media to do film review. Relevant investigation shows that the masses number participating in online media film review is more than half, and basically all the people has browsed online media movies among the respondents. There are nearly $70 \%$ of the people said that the time to surf the Internet media movies is much more than the reading time of the traditional film reviews, so it can be proved that the internet film review has been unprecedented attention under the new situation, and the film review people will not be adversely affected in terms of commercial interests, at the same time, they do not have to bear the relevant responsibilities. There is more freedom in the expression of speech, so this form will help the general public to express their true feelings in their hearts. Therefore, the network media film reviews also had a very enthusiastic and loyal fans, which has a greater advantage compared with the previous traditional film reviews.

Many traditional movie critic person joined into the online movie review. Since the last few years, about thirty professional traditional film critics established the www.mvshow.net, and they have opened their own movie reviews to attract the masses to do a review for the recent films. The content of the film evaluation includes both the literary and artistic atmosphere of the traditional film criticism and the entertainment atmosphere affiliating in the Internet media movie reviews. 
Therefore, it is effective to allow professional film critics to communicate with online film critics, make them publish his own unique insights, so that there can be more and more different movie reviews. In addition, the traditional film critics have also found that the new network media film review will not only be able to let the audience know and browse the film under the new situation, but it has greater convenience than the traditional forms of newspapers, magazines and other related media.

Online movie reviews added more life spoken language. In the network media film reviews under the new situation, the languages used are usually spoken, popular language in life, because speaking is from the life, so that the communication is more cordial. For example, when the commenting some films, some network review people will use the sentence: "you can you up, no can no bibi", "It makes me feel sad", through a series of personalized evaluation languages to express their own original ideas. These popular language replaced the terminology for professional film reviews in the traditional movie reviews. The form of expression of such films shortens the distance between the audience and the film and makes people feel very relaxed.

Film review form got innovation. With the development of network information technology, the online movie reviews are no longer limited to the original film evaluation method, but gradually occurred a lot of different ways of online movie reviews. For example, a lot of websites have been recommended to vote on the way to evaluate the film's exciting. The way of this comment is in favor of other viewers to decide whether or not to watch the movie when choosing a movie. There are some websites uses the scoring mechanism to evaluate the quality of the film, so that it will be able to make the majority of the audience choose the proper film combined with the level of scores. This kind of voting, scoring form of online media film review has a high reliability, and the reason is that each one network of movie critics are anonymous voting, usually not involved in any commercial interest, only to implement the evaluation simply according to their own liking, so the voting, scoring film reviews have a very high reference value.

\section{Conclusion}

With the rapid development of network information technology, the new way of network media film reviews has been further improved, and the form of network new media film review has gradually replaced the traditional form of film review, which promoted the development and progress of the movie industry to a great extent. At present, the online media film review developed under the new situation can not be ignored for the production and innovation in the film industry. Therefore, we must pay more attention to the healthy and sustainable development of the online media film review to clear the correct direction of the development of China's film industry review.

\section{Reference}

[1] Li Shuying. The study of movie reviews in network communication [D]. Southwestern University, 2014

[2] Guo Wei. Analysis of emotion mining in online movie reviews [D]. Jilin University, 2010

[3] He Xi. New media form [D]. China Academy of Arts, 2008

[4] Lou Shimin, Dingyue yuan. New period network new media movie review analysis [J]. movie literature, 2013,21:25-26.

[5] Wang Lu. Internet movie reviews the sentiment analysis [J]. tomorrow fashion, 2016,12:260.

[6] Lin Dan. Analysis of the new situation of the new network media film review [J]. Shenzhou, 2012,35:29. 